\title{
Effect of Hypophysectomy on the Adrenal 17-Hydroxycortico- steroid Secretion in Response to Eserine in Dogs
}

\author{
Hiromi Tanigawa, Ryozo Higashi and Tatuzi Suzuki \\ Department of Physiology (Prof. T. Suzuki), \\ Nagasaki University School of Medicine, Nagasaki
}

\begin{abstract}
Dogs, anesthetized with sodium pentobarbital, were used. Adrenal venous blood was collected and analyzed for 17-hydroxycorticosteroids (17-OHCS). In intact (non-hypophysectomized) dogs the adrenal 17-OHCS secretion rates increased after injection of eserine $(0.2 \mathrm{mg} / \mathrm{kg})$ and reached $0.75-1.41 \mu \mathrm{g} / \mathrm{kg} / \mathrm{min}$, while they were $0-0.19 \mu \mathrm{g} / \mathrm{kg} / \mathrm{min}$ before injection. In hypophysectomized dogs an injection of the same dose of eserine did not induce any definite change in adrenal 17-OHCS secretion. Thus, it is concluded that the stimulatory effect of eserine on the adrenal cortical secretion is mediated through pituitary adreno. corticotrophin release.
\end{abstract}

Dordoni and Fortier ${ }^{1}$ showed that eserine induced a depletion of the adrenal ascorbic acid in the rat. Direct evaluation of adrenal cortical secretion in response to eserine has been done in our laboratory. It has been shown that an intravenous injection of eserine causes marked increase in the adrenal 17hydroxycorticosteroid (17-OHCS) secretion in anesthetized ${ }^{2}$ and conscious ${ }^{3}$ dogs, though the magnitude of increase in the former is somewhat smaller than that in the latter. Little has been explored, however, about the site of action of eserine in causing adrenal cortical secretion.

The present study describes the effect of hypophysectomy on the adrenal 17-OHCS secretion in response to eserine.

\section{MeThoDs}

Adult mongrel dogs, weighing from 8.0 to $17.9 \mathrm{~kg}$, were anesthetized with intravenous sodium pentobarbital (Nembutal, Abbott).

In 4 intact (non-hypophysectomized) dogs, the adrenal vein cannulation was performed by a modification of the method of Satake and his co-workers, ${ }^{4}$ as was done in experiments of Suzuki, Yamashita and Mitamura, ${ }^{5}$ 18-20 hours before the start of each experiment. Eserine salicylate (Merck) was dissolved in $0.9 \%$ saline solution and was injected intravenously in a dose of $0.2 \mathrm{mg}$ per $\mathrm{kg}$ of body weight in 30 seconds.

Received for publication, November 13, 1967. 
The same dose of eserine was injected intravenously in other 4 dogs, in which the hypophysectomy had been performed by transbuccal method about 3 hours before experiments. In this group of dogs, the adrenal vein cannulation was completed just before the start of observations. Adrenal venous blood was collected 30 and 10 minutes before and 10,25, 40,60,90 and 120 minutes after injection of eserine. In order to examine the adrenal cortical responsiveness in hypophysectomized dogs, ACTH (Organon) was infused at the end of experiments in a dose of $2 \mathrm{IU} / \mathrm{kg}$ over 5 minutes and adrenal venous blood was collected 15 and 30 minutes after the start of ACTH infusion.

After centrifugation of blood samples, adrenal venous plasma was analyzed for 17-OHCS by the method of Nelson and Samuels. ${ }^{6}$

\section{Results aNd Discussion}

The data concerning the adrenal $17-\mathrm{OHCS}$ secretion rates are summarized in Table 1 and the mean values of secretion rates in intact and hypophysectomized dogs are presented in Fig. 1.

Suzuki and co-workers ${ }^{3}$ showed that an intravenous injection of eserine in a dose of $0.3 \mathrm{mg} / \mathrm{kg}$ increased markedly the adrenal $17-0 \mathrm{HCS}$ secretion in conscious dogs, the maximal secretion rates after eserine being $1.47-1.97 \mu \mathrm{g} / \mathrm{kg} / \mathrm{min}$. Similar results were obtained by $\mathrm{Otsuka}^{2}$ in dogs anesthetized with sodium pentobarbital. In his experiments the maximal secretion rates of $17-0 H C S$ after eserine were $0.64-1.60 \mu \mathrm{g} / \mathrm{kg} / \mathrm{min}$.

In the present study, eserine was applied intravenously in a dose of $0.2 \mathrm{mg} / \mathrm{kg}$ instead of $0.3 \mathrm{mg} / \mathrm{kg}$. The secretion rates of $17-\mathrm{OHCS}$ increased definitely and reached the peak levels $(0.75-1.41 \mu \mathrm{g} / \mathrm{kg} / \mathrm{min})$ within 40 minutes after injection of eserine,

TABLE 1. Adrenal 17-hydroxycurticosteroid secretion following injection of eserine in 4 intact and 4 hypophysectomized dogs

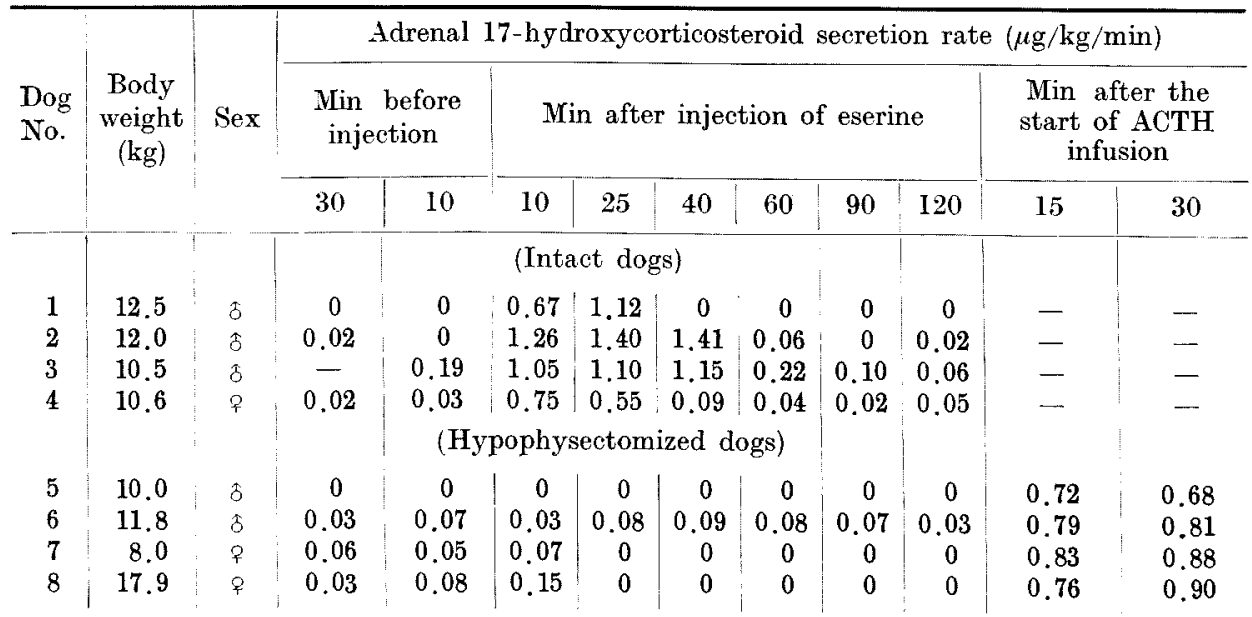




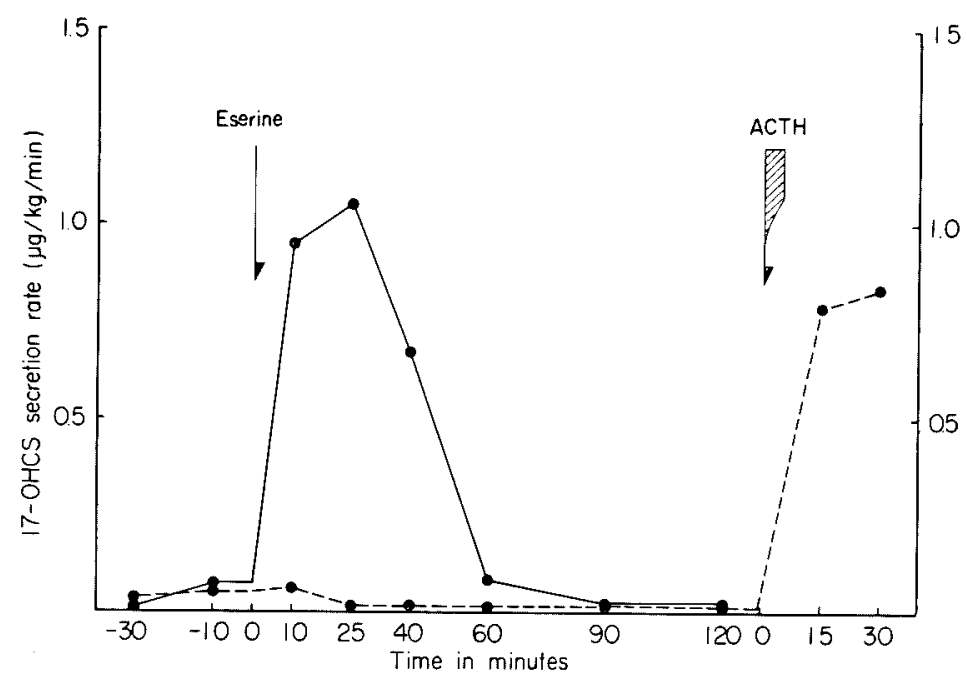

Fig. 1. Adrenal 17-hydroxycorticosteroid secretion rates (average values) in intact dogs (solid line) and in hypophysectomized dogs (dotted line) after injection of eserine in a dose of $0.2 \mathrm{mg} / \mathrm{kg}$ and after infusion of ACTH in a dose of $2 \mathrm{IU} / \mathrm{kg}$.

while they were $0-0.19 \mu \mathrm{g} / \mathrm{kg} / \mathrm{min}$ before injection. Within 60 minutes after injection the adrenal 17-OHCS secretion rate returned almost to the pre-injection level.

Experiments in hypophysectomized dogs have been designed to reveal whether the stimulatory effect of eserine on the adrenal cortical secretion is mediated by the pituitary adrenocorticotrophin secretion. In this group of dogs, no definite rise in 17-OHCS secretion rates was observed following intravenous injection of eserime in a dose of $0.2 \mathrm{mg} / \mathrm{kg}$, the secretion rates being $0-0.08$ and $0-0.15 \mu \mathrm{g} / \mathrm{kg} / \mathrm{min}$ before and after eserine, respectively. After intravenous infusion of ACTH in a dose of $2 \mathrm{IU} / \mathrm{kg}$, the adrenal 17 -OHCS secretion rates increased to $0.68-0.90 \mu \mathrm{g} / \mathrm{kg} / \mathrm{min}$. Thus, the adrenal cortex in these hypophysectomized dogs was proved to be still responsive to ACTH.

These results may offer the evidence that eserine increases the adrenal cortical secretion through the pituitary adrenocorticotrophin release.

\section{References}

1) Dordoni, F. \& Fortier, C. Effect of eserine and atropine on ACTH release. Proc. Soc. exp. Biol. Med. (N.Y.), 1950, 75, 815-816.

2) Otsuka, K. Effects of atropine, eserine and tetramethylammonium on the adrenal 17-hydroxycorticosteroid secretion in anesthetized dogs. Tohoku J. exp. Med., 1966, 88, $165-170$.

3) Suzuki, T., Hirai, K., Yoshio, H., Kurouji, K-I. \& Hirose, T. Effect of eserine and atropine on adrenocortical hormone secretion in unanaesthetized dogs. $J$. Endocr., $1964,31,81-82$.

4) Satake, Y., Sugawara, T. \& Watanabe, M. A method for collecting the blood from the suprarenal gland in the dog, without fastening. narcotizing, laparotomy or provoking any pain. Tohoku J. exp. Med., 1927, 8, 501-534. 
5) Suzuki, T., Yamashita, K. \& Mitamura, T. Effect of ether anesthesia on 17hydroxycorticosteroid secretion in dogs. Amer. J. Physiol., 1959, 197, 1261-1262.

6) Nelson, D.H. \& Samuels, L.T. A method for the determination of 17-hydroxycorticosteroids in blood: 17-Hydroxycorticosterone in the peripheral circulation. J. clin. Endocr., 1952, 12, 519-526. 